\title{
Expanded Capsules with Reversibly Added Spacers
}

\section{Supporting Information}

Dariush Ajami, Julius Rebek, Jr*.

The Skaggs Institute for Chemical Biology and the Department of Chemistry, The Scripps Research Institute MB-26, 10550 North Torrey Pines Road, La Jolla, California 92037

jrebek@scripps.edu

\section{General Information}

All reagents were obtained from commercial suppliers and used without further purification. NMR spectra were recorded on a Bruker DRX-600 spectrometer. Deuterated NMR solvents were obtained from Cambridge Isotope Laboratories, Inc., Andover, MA, and used without further purification. 
Upfield regions of the ${ }^{1} \mathrm{H}$ NMR spectra $\left(600 \mathrm{MHz}\right.$, Mesitylene $\left.d_{12}\right)$ of 1 $(2 \mathrm{mM})$ with $5 \mathrm{a}(6 \mathrm{mM})$ and $(15 \mathrm{mM})$ of $\mathrm{C}_{16} \mathrm{H}_{34}$ to $\mathrm{C}_{21} \mathrm{H}_{44}$ :

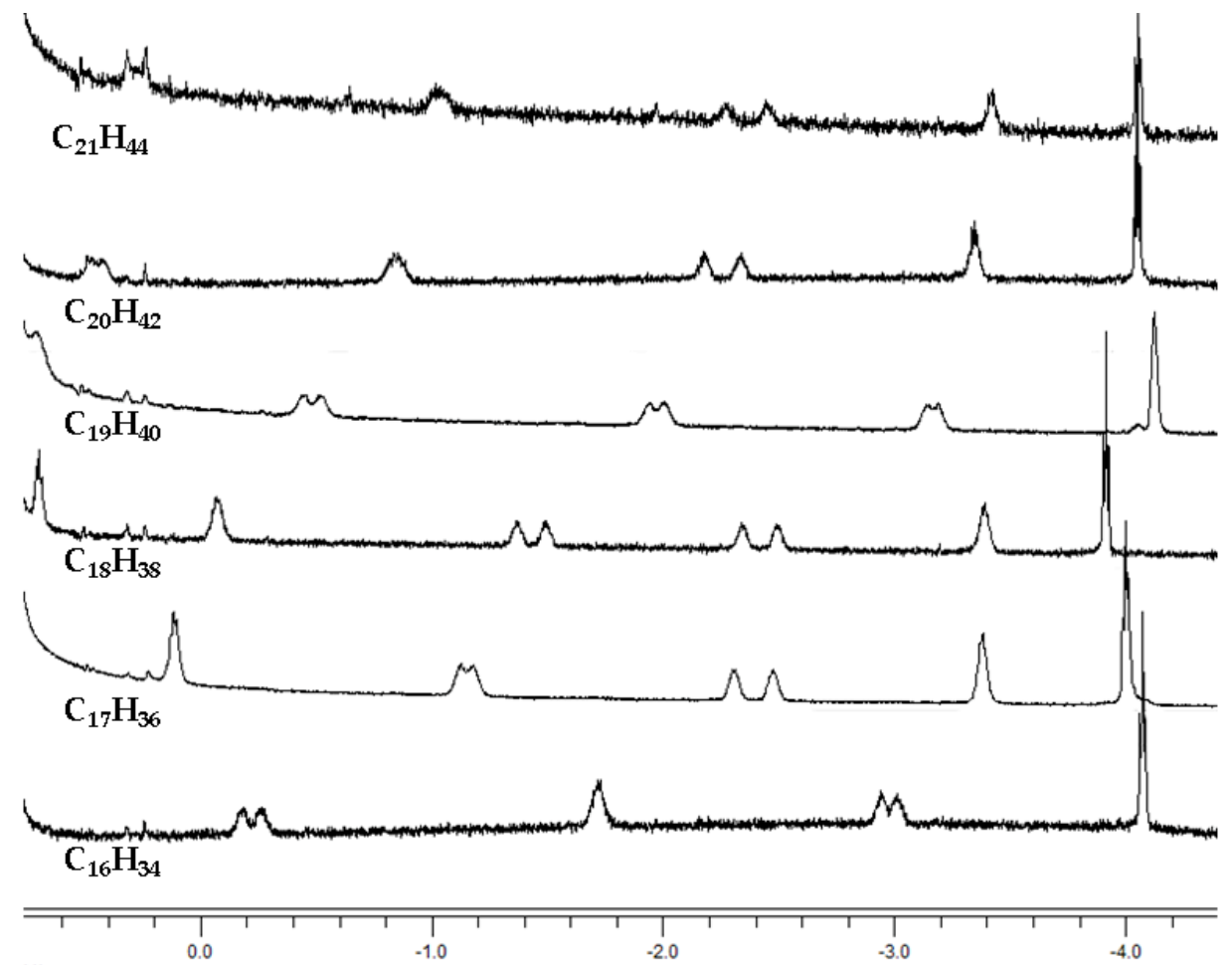


${ }^{1} \mathrm{H}$ NMR Assignment of encapsulated heptadecane in 6.6:

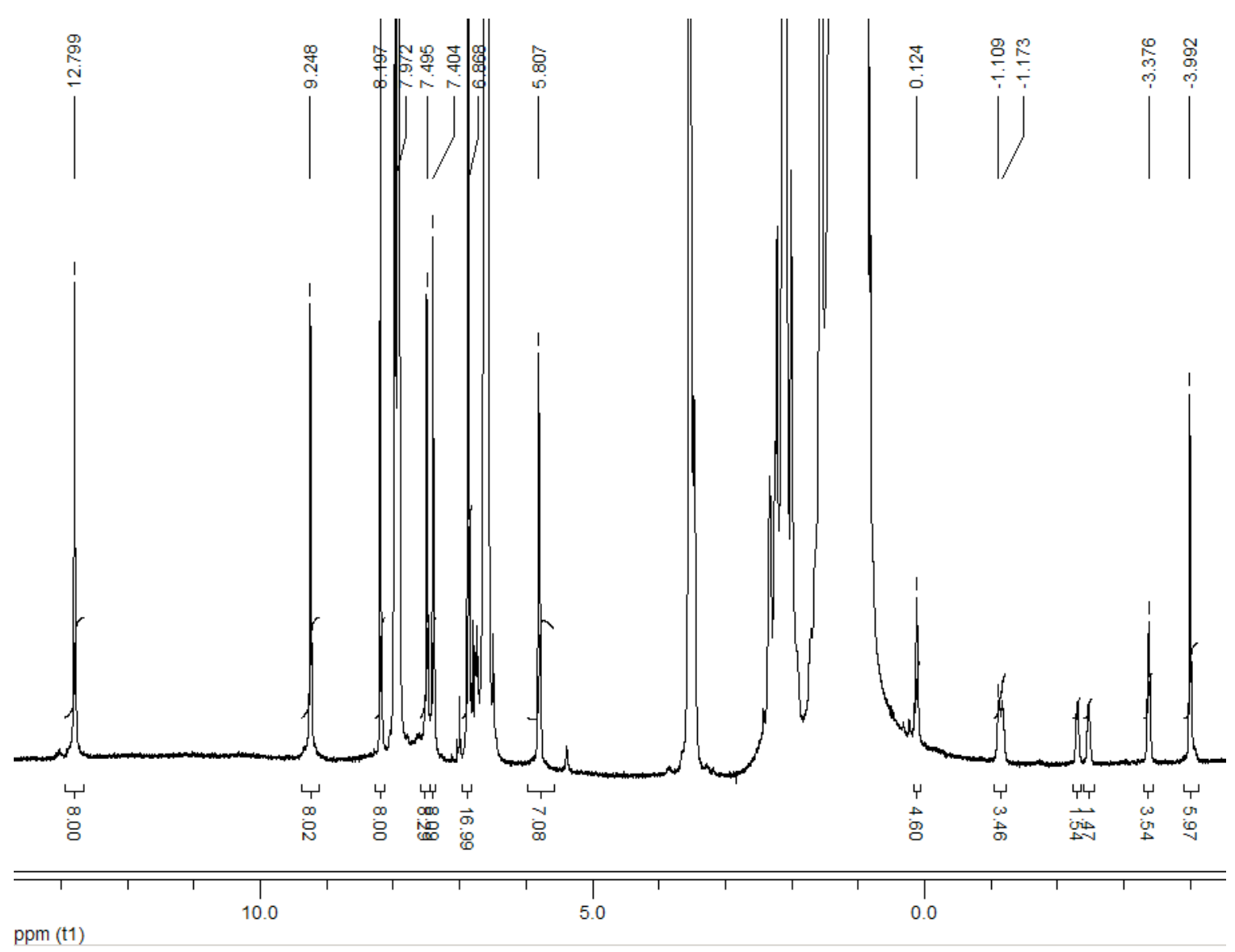


${ }^{1} \mathrm{H}$ NMR Assignment of encapsulated octadecane in 6.6:

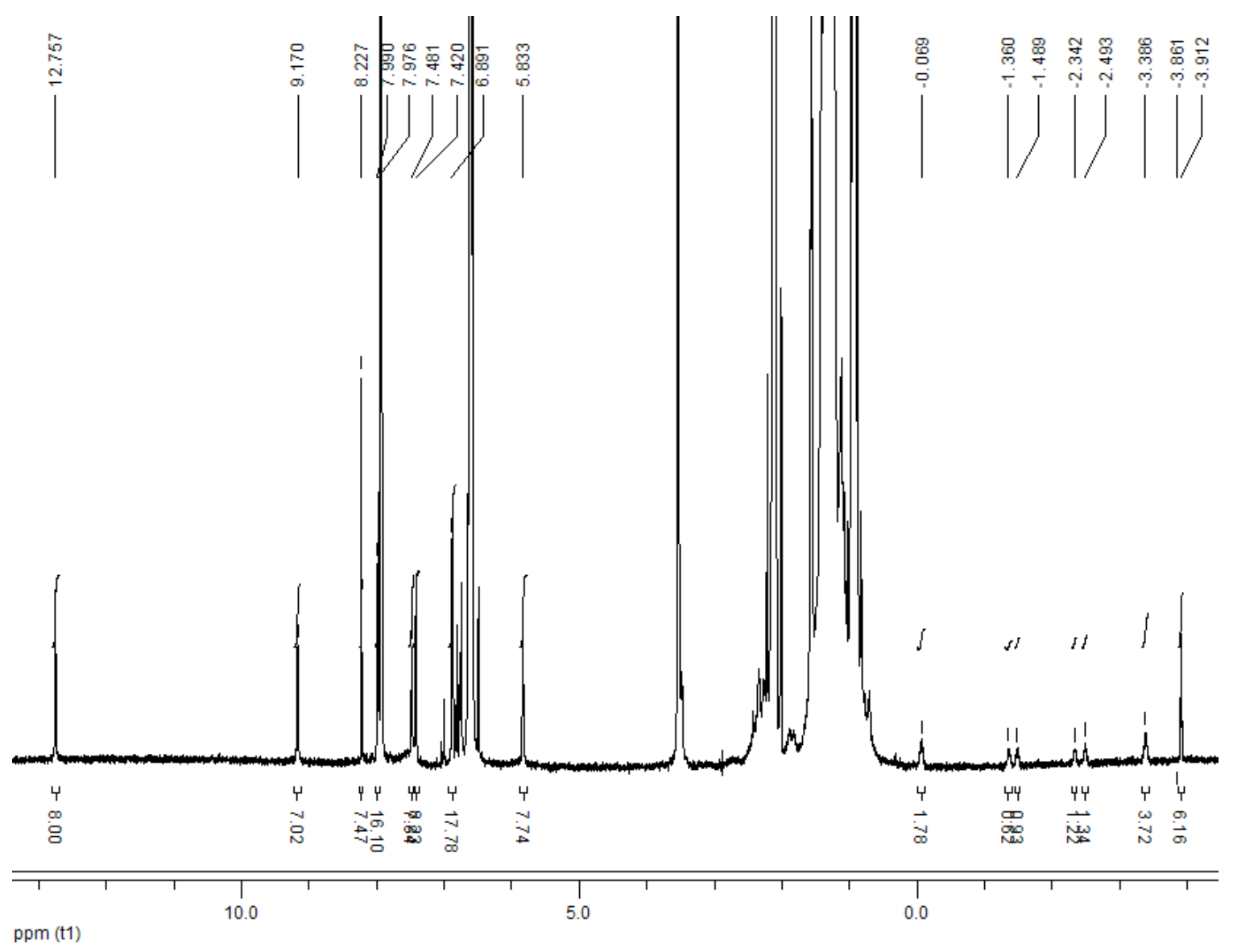


EXSY spectra of encapsulated heptadecane in 6.6 :

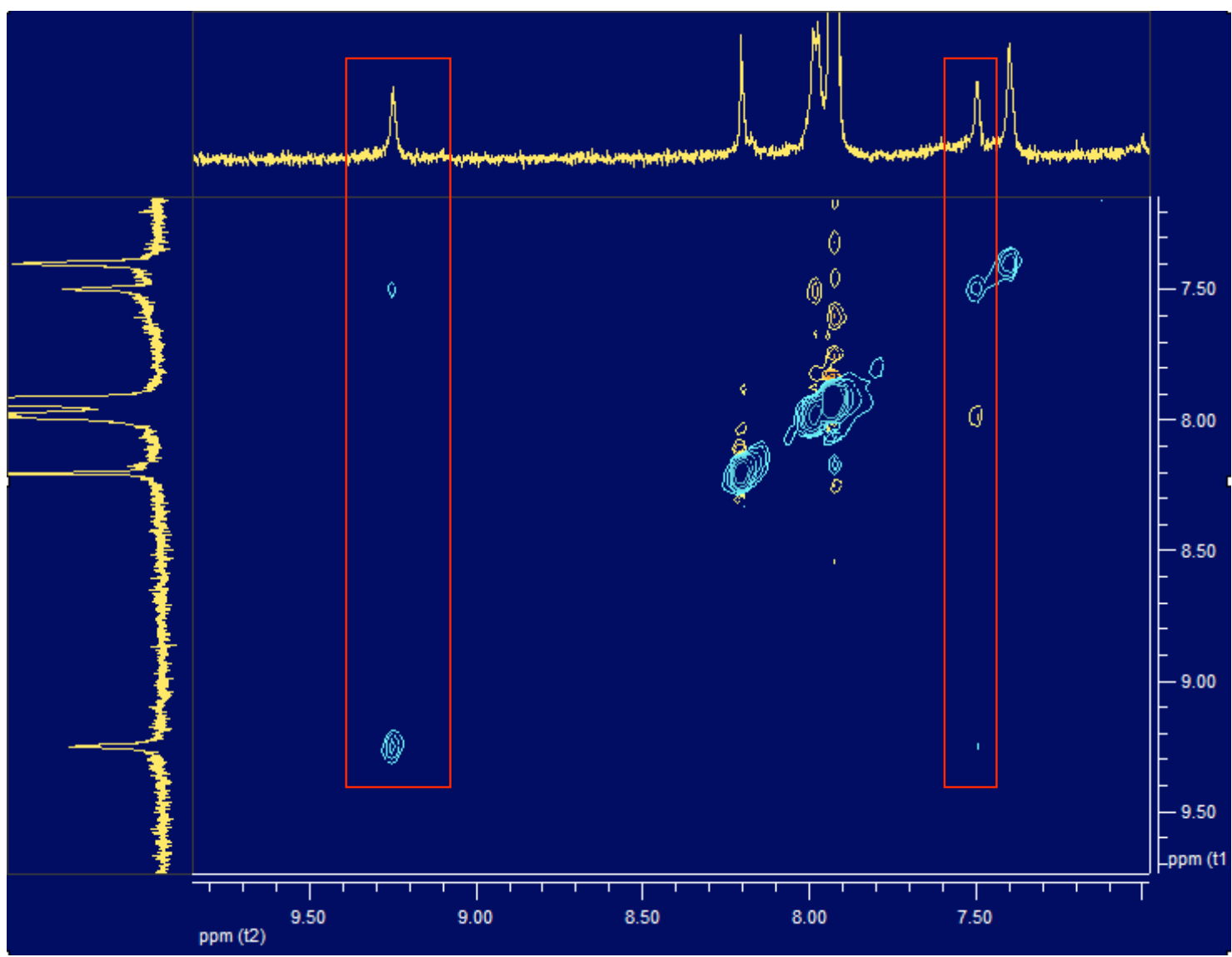

There are two signals for the glycoluril N-H's, one at $\sim 9.3 \mathrm{ppm}$ and another at $\sim 7.5$ ppm, and these undergo chemical exchange in the EXSY spectra 
DOSY spectra of encapsulated heptadecane in 6.6 :

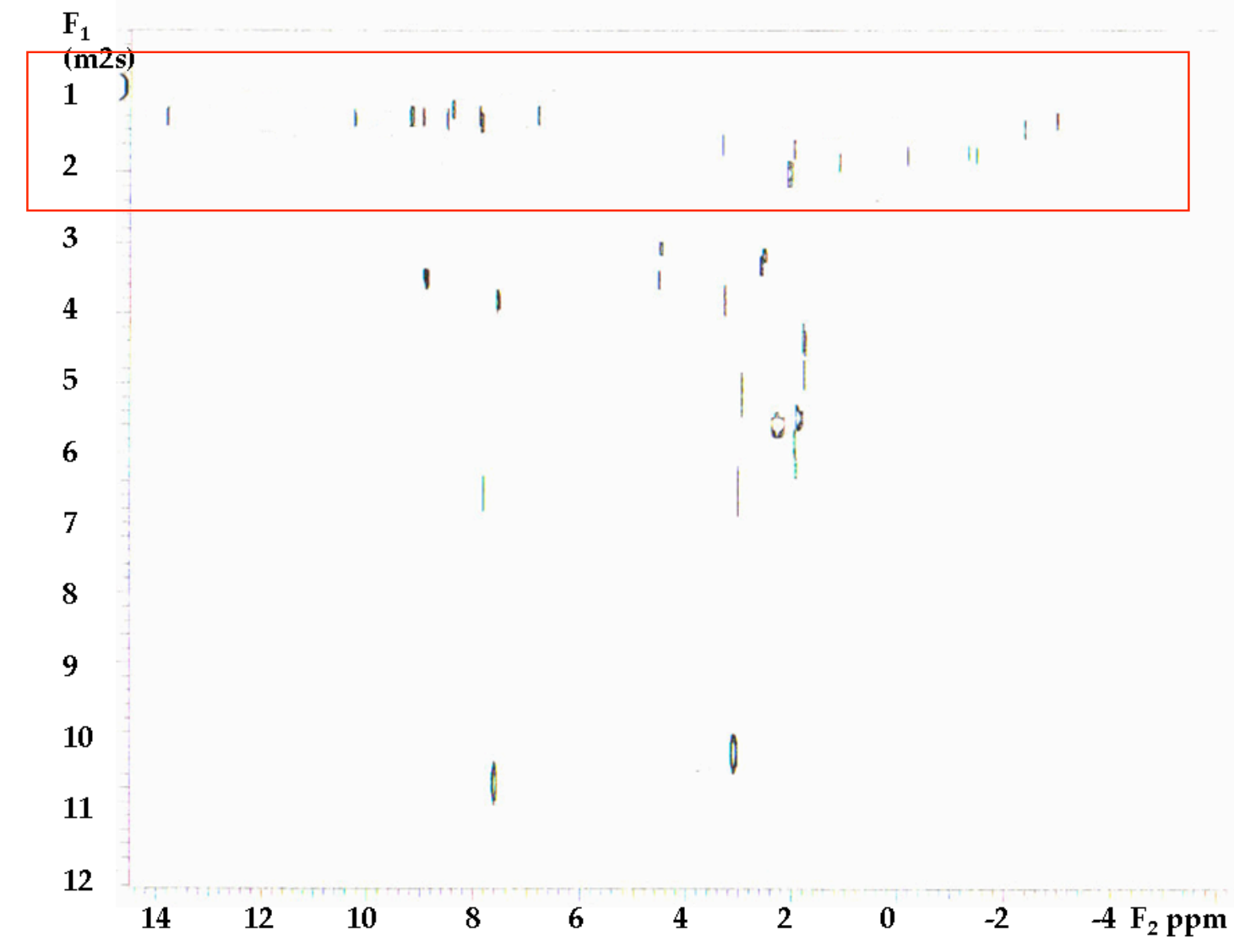


Downfield regions of ${ }^{1} \mathrm{H}$ NMR spectra $\left(600 \mathrm{MHz}\right.$, Mesitylene $\left.d_{12}\right)$ of 1 (2 mM) with

3) $5 \mathrm{~b}(6 \mathrm{mM})$ and heptadecane $(15 \mathrm{mM})$

2) $5 \mathrm{a}(6 \mathrm{mM})$ and heptadecane $(15 \mathrm{mM})$

1) $5 \mathrm{a}(3 \mathrm{mM}), 5 \mathrm{~b}(3 \mathrm{mM})$ and heptadecane $(15 \mathrm{mM})$

The $a$ and $b$ are amide peaks and $c$ is imide peak.

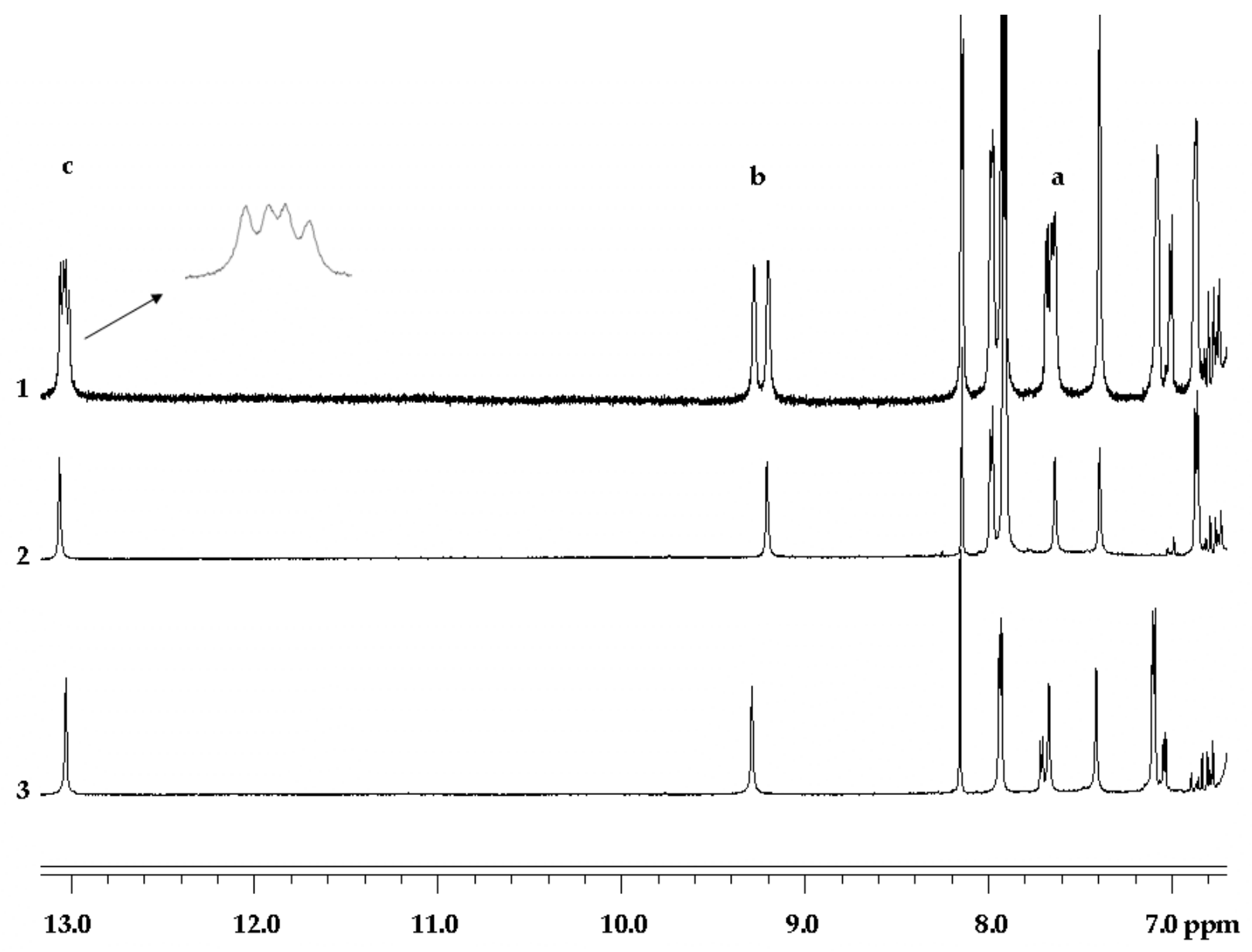


${ }^{1} \mathrm{H}$ NMR spectra $\left(600 \mathrm{MHz}\right.$, Mesitylene $\left.d_{12}\right)$ of

(a) $1(2 \mathrm{mM})$ and $5 \mathrm{a}(6 \mathrm{mM})$ with heptadecane $(15 \mathrm{mM})$

(b) 4,4'-Dimethyl-trans-stilbene 4 (15 mM) added to the sample (a) .

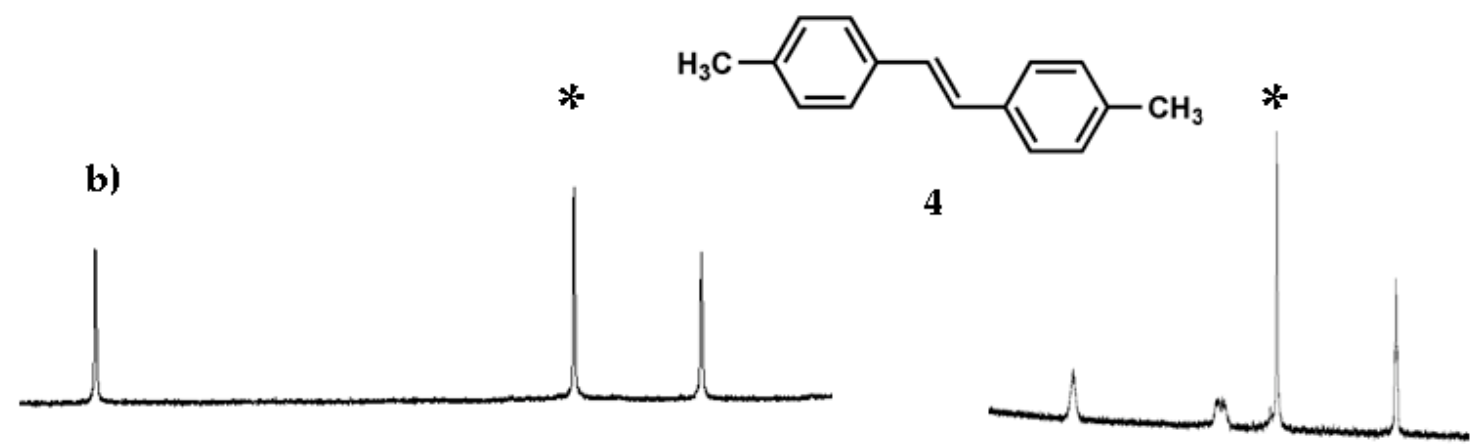

a)
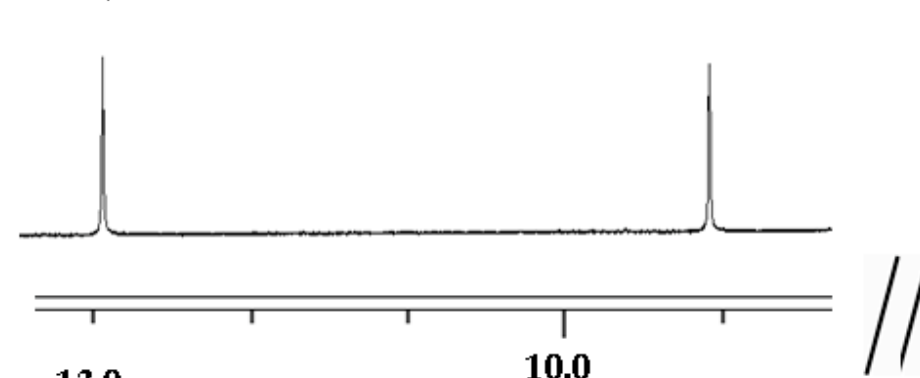

13.0

10.0

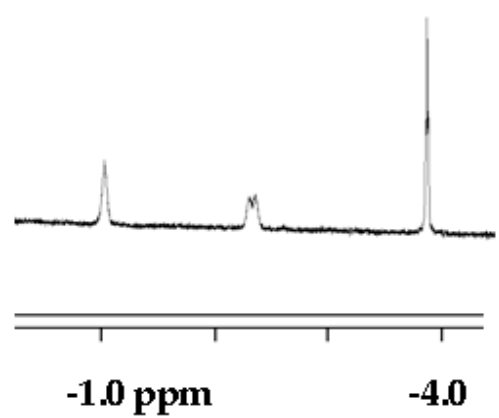


${ }^{1} \mathrm{H}$ NMR spectra $\left(600 \mathrm{MHz}\right.$, Mesitylene $\left.d_{12}\right)$ of $1(2 \mathrm{mM})$ and $5 \mathrm{a}(6 \mathrm{mM})$ with Heptadecene (15mM), (a) at room temperture (b) at $365 \mathrm{~K}$. .
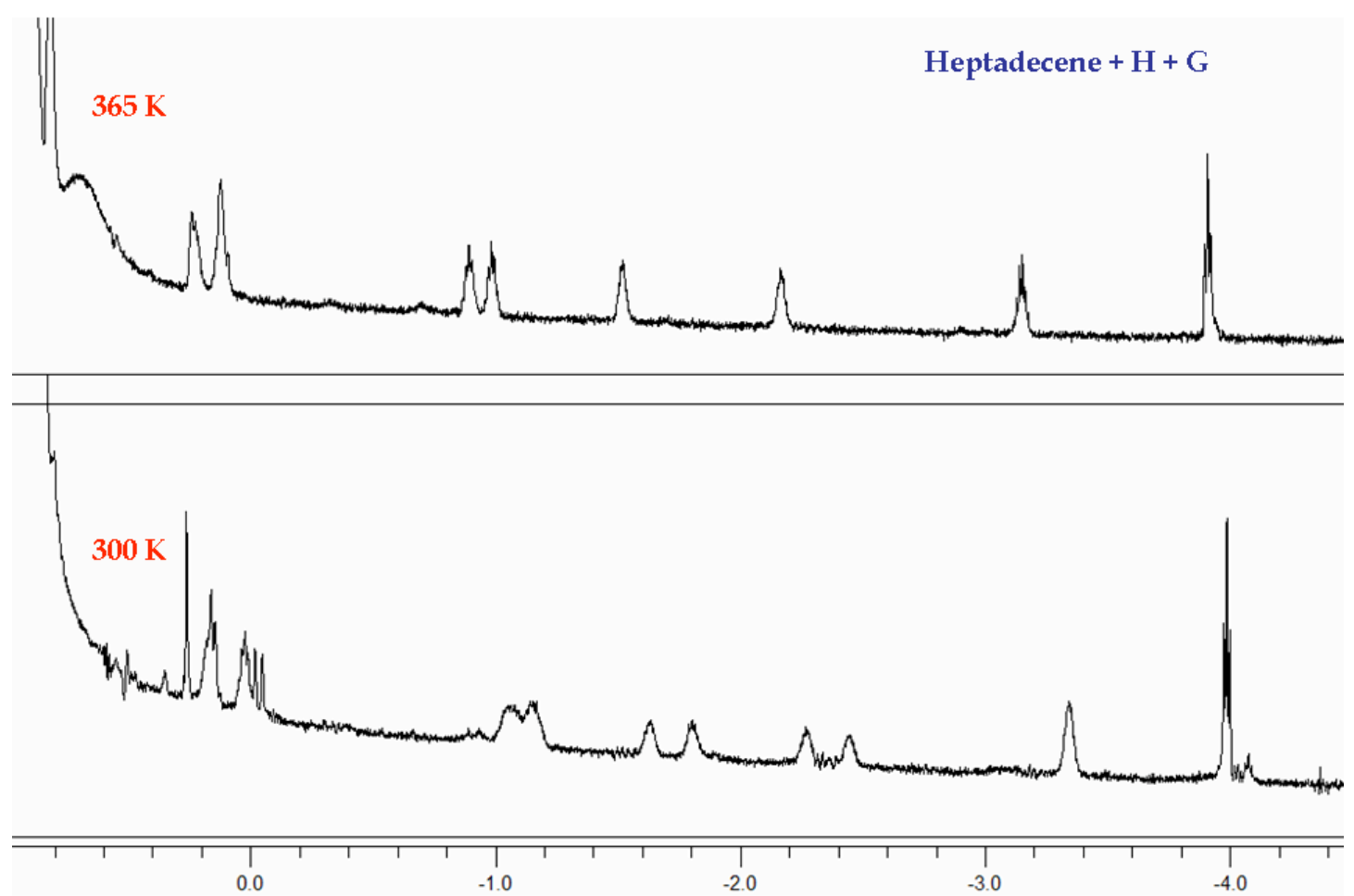
${ }^{1} \mathrm{H}$ NMR spectra $\left(600 \mathrm{MHz}\right.$, Mesitylene $\left.d_{12}\right)$ of $1(2 \mathrm{mM})$ and $5 a(6 \mathrm{mM})$ with Hexadecyne $(15 \mathrm{mM})$ and pentxadecyne $(15 \mathrm{mM})$.
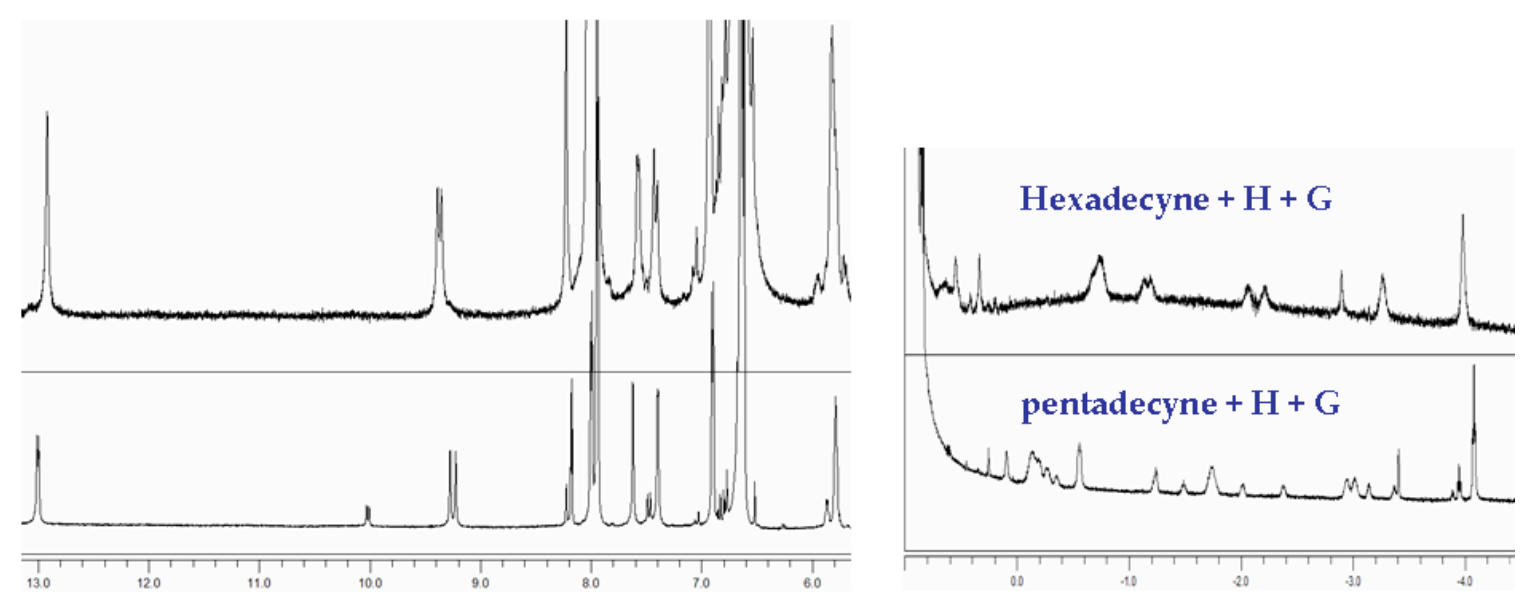

${ }^{1} \mathrm{H}$ NMR spectra $\left(600 \mathrm{MHz}\right.$, Mesitylene $\left.d_{12}\right)$ of $1(2 \mathrm{mM})$ and $5 \mathrm{a}(6 \mathrm{mM})$ with 4-heptyl, 4'-carbonitrile biphenyl 4 (15mM) 


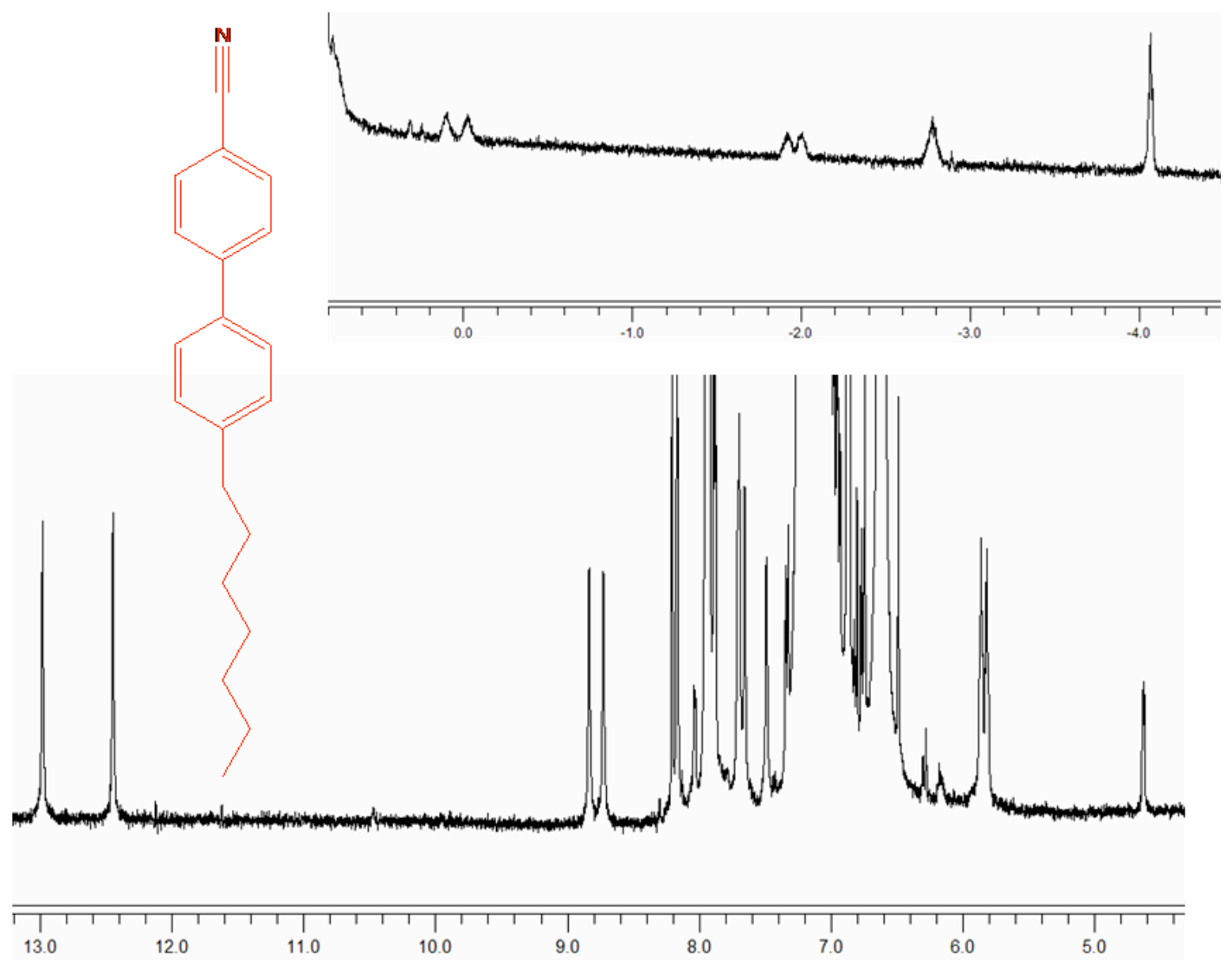

${ }^{1} \mathrm{H}$ NMR spectra $\left(600 \mathrm{MHz}\right.$, Mesitylene $\left.d_{12}\right)$ of $1(2 \mathrm{mM})$ and $5 \mathrm{a}(6 \mathrm{mM})$ with (down) 4-undecyl benzene $3 a(15 \mathrm{mM})$ (up) 4-dodecyl benzene $3 \mathrm{~b}$ (15mM) 


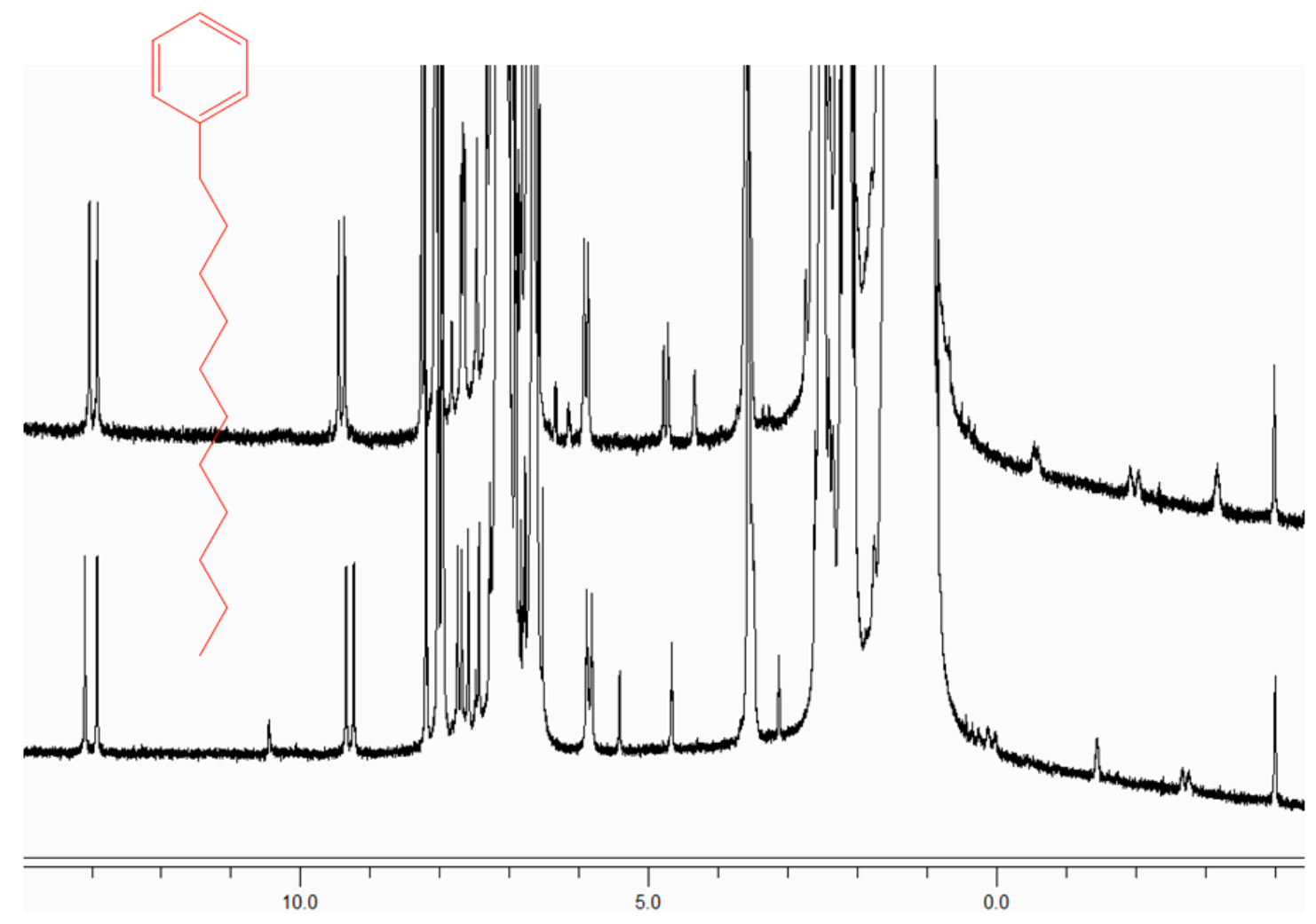

